\title{
CAPIM-TIFTON 85 CULTIVADO EM SISTEMA ALAGADO CONSTRUÍDO COM ELEVADAS TAXAS DE APLICAÇÃO
}

Fabiana de Amorim ${ }^{1}$, Ronaldo Fia ${ }^{2}$, Pedro Polegato Pasqualin ${ }^{3}$, Luiz Fernando Coutinho Oliveira ${ }^{2}$, Juliano Rezende Mudado Silva ${ }^{3}$

\section{RESUMO}

Os sistemas alagados construídos (SACs) têm sido utilizados para tratamentos de efluentes, principalmente como unidades terciárias. Apresentam moderado custo de instalação e considerável remoção de nutrientes e a vegetação que o compõem pode ser aproveitada para fins de alimentação animal. Neste trabalho, avaliou-se o desempenho do capim-tifton 85 (Cynodon spp.) no tratamento de água residuária de suinocultura. $\mathrm{O}$ experimento foi conduzido durante 131 dias, em três fases. As taxas de aplicação chegaram a 6.335, 464, e $240 \mathrm{~kg} \mathrm{ha}^{-1} \mathrm{~d}^{-1}$ de DQO, NTK e PT, respectivamente. A cada corte, foram quantificadas massas verde e seca, os teores de nitrogênio, fósforo e proteína bruta. Conclui-se que houve aumento nas concentrações de proteína bruta, NTK e PT no tecido do capim-tifton 85 com o aumento da taxa de aplicação superficial de nutrientes, mas a produtividade de matéria seca reduziu na terceira fase, provavelmente, por fatores como diminuição da temperatura ambiente e excesso de sólidos retidos no SAC. Elevadas taxas orgânicas de aplicação limitaram o desenvolvimento do capim-tifton 85 em termos de matéria seca.

Palavras-chave: Cynodon spp., fertirrigação, nutrientes, água residuária da suinocultura, wetlands construídos.

\section{ABSTRACT}

\section{TIFTON GRASS IN CONSTRUCTED WETLANDS WITH HIGH LOADS}

Constructed wetlands (CWs) have been used for effluent treatment, especially as tertiary units. They present moderate cost of installation and considerable nutrient removal. The vegetation utilized in CWs can be used for animal feeding. In this paper, we evaluate the performance of Tifton 85 grass (Cynodon spp.) for the treatment of swine wastewater. The experiment was conducted for 131 days in three phases. Application rates reached levels of 6335, 464 and 240 $\mathrm{kg} \mathrm{ha}^{-1} \mathrm{~d}^{-1}$ of COD, TKN and TP, respectively. At each cutting the green and dry mass and the levels of nitrogen, phosphorus and crude protein were quantified. It was found that there was an increase in the concentrations of crude protein, NTK and TP in the Tifton 85 grass tissues with increasing rate of surface nutrient application, but the dry matter yield decreased in the third phase, probably as a result of factors such as decreasing temperature and excess solids retained in the $\mathrm{CW}$. Elevated organic application loadings reduced the development of Tifton 85 grass with respect to dry matter.

Keywords: Cynodon spp., fertigation, nutrients, swine wastewater, wetlands systems,

\section{Recebido para publicação em 17/10/2014. Aprovado em 13/03/2015.}

1 - Eng ${ }^{\circ}$ Agrícola, Doutoranda em Recursos Hídricos em Sistemas Agrícolas, Depto. de Engenharia, UFLA. fabianadeamorim@, yahoo.com.br

2 - Prof. Doutor, Departamento de Engenharia, UFLA/Lavras - MG

3 - Graduando em Engenharia Ambiental e Sanitária, Depto. de Engenharia, UFLA/Lavras - MG 


\section{INTRODUÇ̃̃O}

Os sistemas alagados construídos (SACs) são sistemas artificiais de tratamento de águas residuárias projetados e construídos para simular os processos naturais que envolvem a vegetação adaptada a condições alagadas, substratos para fixação de raízes e crescimento de biofilme com microrganismos associados auxiliando na remoção de diversos contaminantes. Sendo assim, projetados para utilizar os mesmos processos que ocorrem em áreas úmidas naturais, mas sob ambiente mais controlado (KADLEC; WALLACE, 2008).

Os SACs podem ser categorizados, de acordo com os parâmetros de dimensionamento, como critérios hidráulicos, tipo de crescimento de plantas macrófitas e tipo de fluxo (horizontal e vertical). Cada tipo de escoamento proporciona diferente grau de interação do efluente com as raízes, rizomas e biota microbiana (KADLEC; WALLACE, 2008). Os sistemas alagados construídos apresentam elevado potencial de aplicação no tratamento de diversas águas residuárias, sendo utilizados há décadas (VYMAZAL, 2010).

Diversas plantas têm sido utilizadas e indicadas para vegetação nos sistemas, por ocorrerem naturalmente em locais com condições semelhantes ou suportarem as condições anaeróbias/anóxicas que ocorrem normalmente nos SACs horizontais. Vymazal (2013) realizou revisão sobre as plantas mais utilizadas nesse sistema, identificou cerca de 150 espécies no mundo, predominando os gêneros Typha sp., Scirpus sp., Pragmites sp., Juncus sp. e Eleocharis sp. O autor verificou apenas um SAC utilizando o gênero Cynodon (Cynodon dactylon) na América do Norte. Osaliya et al. (2011) avaliaram o desempenho de Cynodon dactylon) no tratamento de drenagem ácida de minas em SACs em Uganda; enquanto Johns et al. (2014) testaram a resistência do Cynodon dactylon cultivados em SACs em relação à salinidade da água.

No Brasil, as gramíneas do gênero Cynodon, como capim-tifton 85, têm sido utilizadas experimentalmente em SACs, pois possui boas características de produção e elevada capacidade de crescimento. O capim-tifton 85 é uma planta perene que permite rápida recuperação pós-cortes, característica desejada no SAC que objetiva a remoção de nutrientes (QUEIROZ, 2004). Embora o capim-tifton seja cultivado em solo bem drenado (OLIVEIRA et al., 2010; FONTANELI et al.,
2012; PEREIRA et al., 2012), tem se adaptado bem aos sistemas alagados construídos.

Matos et al. (2009) avaliando a capacidade extratora de diferentes espécies vegetais para taxa de aplicação de 590,9 $\mathrm{kg} \mathrm{ha}^{-1} \mathrm{~d}^{-1}$ de DQO obteve bons resultados também com Cynodon ssp. Fia et al. (2011) assim como Fia et al. (2014) obtiveram maior remoção de nutrientes com Cynodon ssp. quando comparado com Typha sp.

Além da utilização dos SACs como reatores para remoção de nutrientes, esses, também, são eficientes na remoção de sólidos em suspensão (MATOS et al., 2010), podendo funcionar como decantadores secundários. Os organismos presentes nesse ambiente podem adaptar-se às características das águas residuárias e utilizar os vários poluentes orgânicos e inorgânicos em processos metabólicos (KADLEC; WALLACE, 2008).

Assim, o objetivo deste trabalho foi verificar o desempenho do capim-tifton 85 cultivado em SAC com elevadas taxas de aplicação de ARS.

\section{MATERIAL E MÉTODOS}

O experimento foi conduzido na área de tratamento de efluentes do Departamento de Zootecnia, sob a responsabilidade do Departamento de Engenharia, na Universidade Federal de Lavras (UFLA), Minas Gerais, com coordenadas geográficas de $21^{\circ} 14^{\prime}$ latitude sul e $45^{\circ} 00^{\prime}$ longitude oeste, e a altitude média de $920 \mathrm{~m}$.

O sistema de tratamento foi instalado em ambiente protegido, com estrutura tipo arco, cobertura de polietileno transparente de baixa densidade (PEBD) de $150 \mathrm{~mm}$, com $12 \mathrm{~m}$ de comprimento por 10 metros de largura, $3 \mathrm{~m}$ de pédireito e arcos de $1,5 \mathrm{~m}$. Nas laterais da estufa foi instalado sombrite $50 \%$ na cor preta, de maneira que a ambiência interna sofria, em relação à externa, pequenas variações.

A água residuária da suinocultura (ARS) foi proveniente da granja suinícola do Departamento de Zootecnia (DZO) da UFLA e após passar por tratamentos preliminares, primário e secundário, foi conduzida continuamente por meio de bomba dosadora para o SAC, construído com 4 chicanas igualmente espaçadas ao longo da estrutura.

As dimensões do SAC foram de $2,0 \mathrm{~m}$ de comprimento por $0,5 \mathrm{~m}$ de largura e $0,70 \mathrm{~m}$ de altura (Figura 1). O SAC foi preenchido com brita zero, como meio de suporte até a altura de $0,55 \mathrm{~m}$,

\section{REVENG}

$$
\text { 241-250p. }
$$

ENGENHARIA NA AGRICULTURA, VIÇOSA - MG, V.23 N.3, MAIO / JUNHO 2015 
compreendendo um volume de vazios de $0,494 \mathrm{~m}^{3}$ $\mathrm{m}^{-3}$. O escoamento subsuperficial ocorreu $0,05 \mathrm{~m}$ abaixo da superfície, totalizando um volume útil de $237 \mathrm{~L}$.
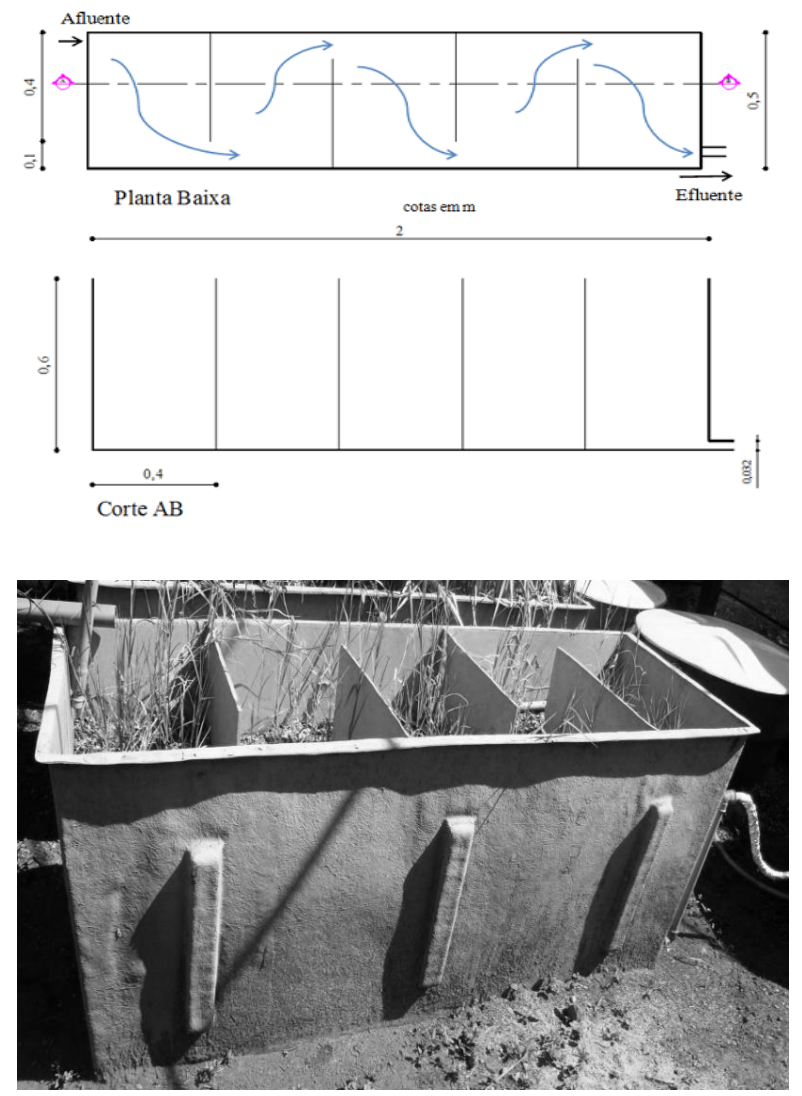

Figura 1. Diagrama esquemático e visão geral do sistema alagado construído chicanado utilizado no tratamento da água residuária da suinocultura.
O SAC utilizado no experimento foi cultivado com capim-tifton 85 (Cynodon spp.). Partes do colmo da planta, provenientes do Setor de Forragicultura do Departamento de Zootecnia da UFLA, foram plantadas em recipientes plásticos, contendo areia e uma mistura de água e ARS na proporção de $1: 1(\mathrm{v} / \mathrm{v})$, para que houvesse o desenvolvimento do sistema radicular. Após 15 dias, ocorreu o plantio no SAC. Esse foi realizado cerca de 40 dias antes de introduzir a ARS no sistema para tratamento, utilizando a densidade de 25 propágulos por $\mathrm{m}^{2}$. A cada 2 dias, nesta etapa inicial, foi feita a aplicação de água e ARS na proporção de 1:1 (v/v), como forma de reposição da água perdida por evapotranspiração da vegetação e evaporação natural do SAC, para que a planta se fixasse e iniciasse o processo de desenvolvimento.

Determinaram-se, duas vezes por semana nas amostras afluente e efluente ao SAC, os valores condutividade elétrica (CE), pelo método da resistividade em condutivímetro de bancada. $\mathrm{O}$ ambiente da casa de vegetação foi monitorado por meio de um termo higrômetro, em que se obteve valores máximos e mínimos dentro da casa de vegetação ao longo do dia. Diariamente, às 7 horas da manhã, foi obtida a temperatura instantânea do ar e do líquido em tratamento.

Para este estudo foram definidas três fases, ao longo do monitoramento (de fevereiro a julho de 2014), sendo os períodos de duração determinados pelo corte da forrageira, que foram efetuados sempre que estas emitiam a primeira inflorescência. Tal fato ocorreu aos 60 dias, após o início do monitoramento do sistema, 32 dias após o primeiro

Quadro 1. Características operacionais médias observadas no sistema alagado construído (SAC) nas diferentes fases de operação do sistema de tratamento.

\begin{tabular}{|l|c|c|c|}
\hline \multirow{2}{*}{ Variáveis } & \multicolumn{3}{c|}{ Fase } \\
\cline { 2 - 4 } & $\mathrm{I}(47 \mathrm{~d})$ & II $(32 \mathrm{~d})$ & III $(52 \mathrm{~d})$ \\
\hline $\mathrm{TDH}(\mathrm{h})$ & 146,3 & 48,2 & 12,7 \\
\hline $\mathrm{Q}\left(\mathrm{m}^{3} \mathrm{~d}^{-1}\right)$ & 0,0439 & 0,1175 & 0,4766 \\
\hline $\mathrm{TAS}_{\mathrm{DQO}}\left(\mathrm{kg} \mathrm{ha}^{-1} \mathrm{~d}^{-1} \mathrm{em}\right.$ termos de DQO) & 850 & 656 & 6.335 \\
\hline $\mathrm{TAS}_{\mathrm{NTK}}\left(\mathrm{kg} \mathrm{ha}^{-1} \mathrm{~d}^{-1} \mathrm{em}\right.$ termos de NTK$)$ & 120 & 130 & 464 \\
\hline TAS $_{\mathrm{PT}}\left(\mathrm{kg} \mathrm{ha}^{-1} \mathrm{~d}^{-1} \mathrm{em}\right.$ termos de PT $)$ & 13 & 51 & 240 \\
\hline
\end{tabular}

Sendo: TDH - tempo de detenção hidráulica teórico; TAS $_{\mathrm{DQO}}$ - taxa de aplicação superficial de demanda química de oxigênio; $\mathrm{TAS}_{\mathrm{NTK}}$ - taxa de aplicação superficial de nitrogênio total Kjeldahl; $\mathrm{TAS}_{\mathrm{PT}}$ - taxa de aplicação superficial de fósforo total; Q - vazão afluente. 
corte das plantas e 50 dias após o segundo corte das plantas, coincidindo com o término das Fases I, II e III, respectivamente. A partir das concentrações médias afluentes de DQO $(1936,558,1329 \mathrm{mg} \mathrm{L}$ $\left.{ }^{-1}\right)$, de NTK $\left(277,110\right.$ e $\left.97 \mathrm{mg} \mathrm{L}^{-1}\right)$ e de PT $(30,43$ e $\left.51 \mathrm{mg} \mathrm{L}^{-1}\right)$, da vazão afluente e da área superficial do SAC, foram utilizadas as equações 1 e 2 para obtenção das características operacionais de monitoramento (Quadro 1).

$\mathrm{TDH}=\frac{\mathrm{Vol}}{\mathrm{Q}}$

$\mathrm{TAS}=\frac{\mathrm{C} \times \mathrm{Q}}{\mathrm{As}}$

em que,

$\mathrm{TDH}=$ tempo de detenção hidráulica teórico $(\mathrm{T})$;

Vol = Volume útil do SAC $\left(\mathrm{L}^{3}\right)$;

$\mathrm{Q}=$ Vazão afluente ao $\mathrm{SAC}\left(\mathrm{L}^{3} \mathrm{~T}^{-1}\right)$;

TAS = taxa de aplicação superficial de DQO ou NTK ou PT $\left(\mathrm{M} \mathrm{L}^{-2} \mathrm{~T}^{-1}\right)$;

As $=$ Área superficial do $\mathrm{SAC}\left(\mathrm{L}^{2}\right)$;

Ao final de cada fase, que coincidiu com o surgimento dos primeiros pedúnculos, o capim foi cortado de 5 a $7 \mathrm{~cm}$ de altura acima do meio suporte, e teve a massa verde quantificada. Em

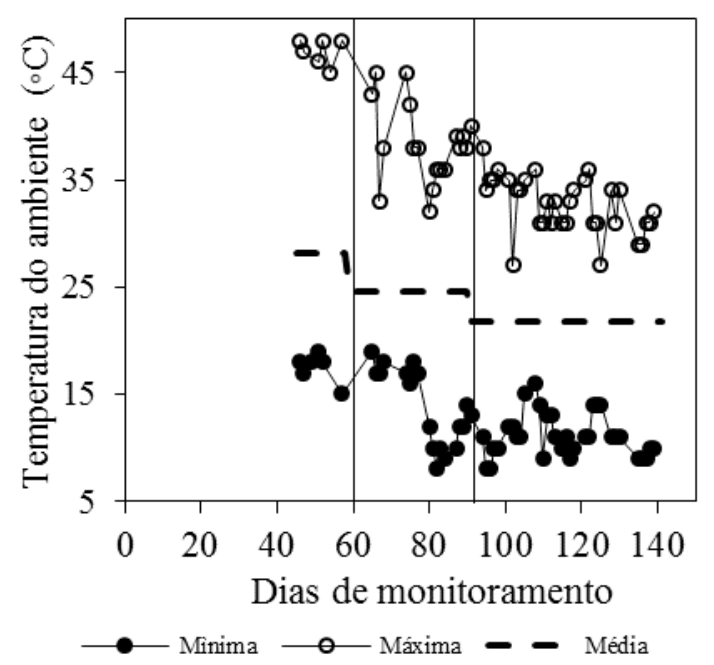

(A) cada chicana coletou separadamente um feixe de capim para compor a amostra da avaliação nutricional. Parte desta amostra foi encaminhada ao Laboratório de Análise de Água Residuária do Núcleo de Engenharia Ambiental e Sanitária do Departamento de Engenharia da UFLA para secagem em estufa com ventilação forçada a 65 ${ }^{\circ} \mathrm{C}$, inicialmente, por $72 \mathrm{~h}$ e, posteriormente, até alcançar massa constante, e assim determinou-se a massa seca.

Para avaliação nutricional, e a partir de uma porção representativa da amostra coletada, o material seco foi triturado em moinho analítico. Foram determinados os teores de nitrogênio total Kjeldahl (NTK), pelo processo semimicro Kjeldahl e fósforo total (PT) por colorimetria, pelo método do ácido ascórbico com digestão ácida. Posteriormente, estimou-se a proteína bruta multiplicando o resultado de NTK por 6,25, seguindo metodologia Kjeldahl, descrita em Silva (2009). As análises foram realizadas em quintuplicata e suas médias apresentadas por meio de estatística descritiva. Os dados de CE foram submetidos ao teste de agrupamento de médias Scott-Knott, ao nível de 5\% de probabilidade, com auxílio do software Sisvar (FERREIRA, 2011).

\section{RESULTADOS E DISCUSSÃO}

Durante o monitoramento do sistema, a temperatura na casa de vegetação apresentou

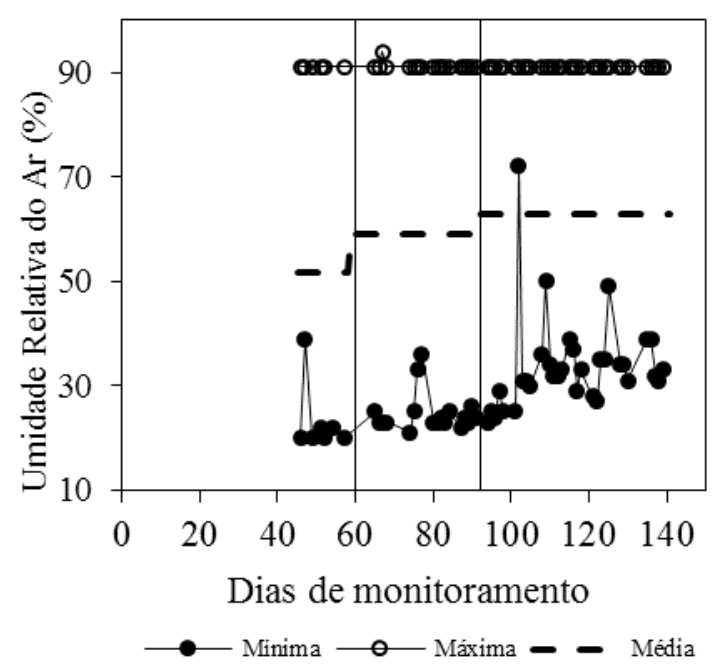

(B)

Figura 2. Variação da temperatura (A) e da umidade (B) ao longo do período de monitoramento dentro da casa de vegetação. 
grande amplitude, variando de $17^{\circ} \mathrm{C}$ a $49^{\circ} \mathrm{C}$, de 11 ${ }^{\circ} \mathrm{C}$ a $37^{\circ} \mathrm{C}$, e de $8{ }^{\circ} \mathrm{C}$ a $33^{\circ} \mathrm{C}$, nas Fases I, II e III, respectivamente (Figura $2 \mathrm{~A}$ ).

A umidade relativa máxima, quase que na totalidade dos dias monitorados foi de $91 \%$, e coincidia com o período de coleta da ARS, entre $7 \mathrm{~h} \mathrm{e} 8 \mathrm{~h}$ da manhã. A umidade relativa do ar tem influência direta na evapotranspiração da planta. Quanto menor a umidade relativa do ar maior é a evapotranspiração da planta (DALMAGO et al., 2006), o que reflete em maior absorção de nutrientes pela vegetação. Deste modo, acredita-se que as condições climáticas contribuíram para que o capim-tifton 85 apresentasse diferentes tempos de maturação (Figura 3).

Embora a Fase I tenha ocorrido durante as temperaturas mais elevadas, o período de desenvolvimento da planta foi maior em relação à Fase II, possivelmente pela adaptação da cultura ao ambiente alagado. Apesar de a Fase II ter menor duração, a produção de massa seca foi semelhante ao resultado da primeira fase, 5,0 $\mathrm{t} \mathrm{ha}^{-1}$ e 4,9 $\mathrm{t} \mathrm{ha}^{-1}$. Nota-se pela Figura 4 que, na Fase I, na parte final do $\mathrm{SAC}$, há menor quantidade de matéria verde. Isso pode ter ocorrido pelo melhor aproveitamento dos nutrientes pelas plantas nas primeiras chicanas.

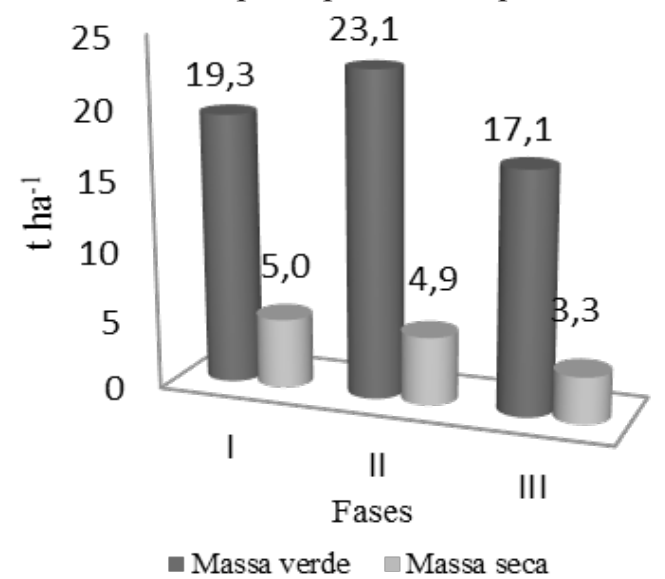

Figura 3. Produção total capim-tifton 85 nas fases de monitoramento em toda área do SAC.

Já na Fase III, com o aumento da carga aplicada (Quadro 1), houve grande aporte de nutrientes e sólidos em termos de matéria orgânica, que se acumulou na superfície da primeira chicana do
SAC, causando um aparente selamento de poros. Embora não tenha sido realizada a avaliação de parâmetros ao longo do comprimento do SAC, o efeito no desenvolvimento das gramíneas pode ser observado (Figura 4C), sendo menor na primeira chicana e crescimento gradativo até o último compartimento do SAC, justificando, assim, menor produção na Fase III.
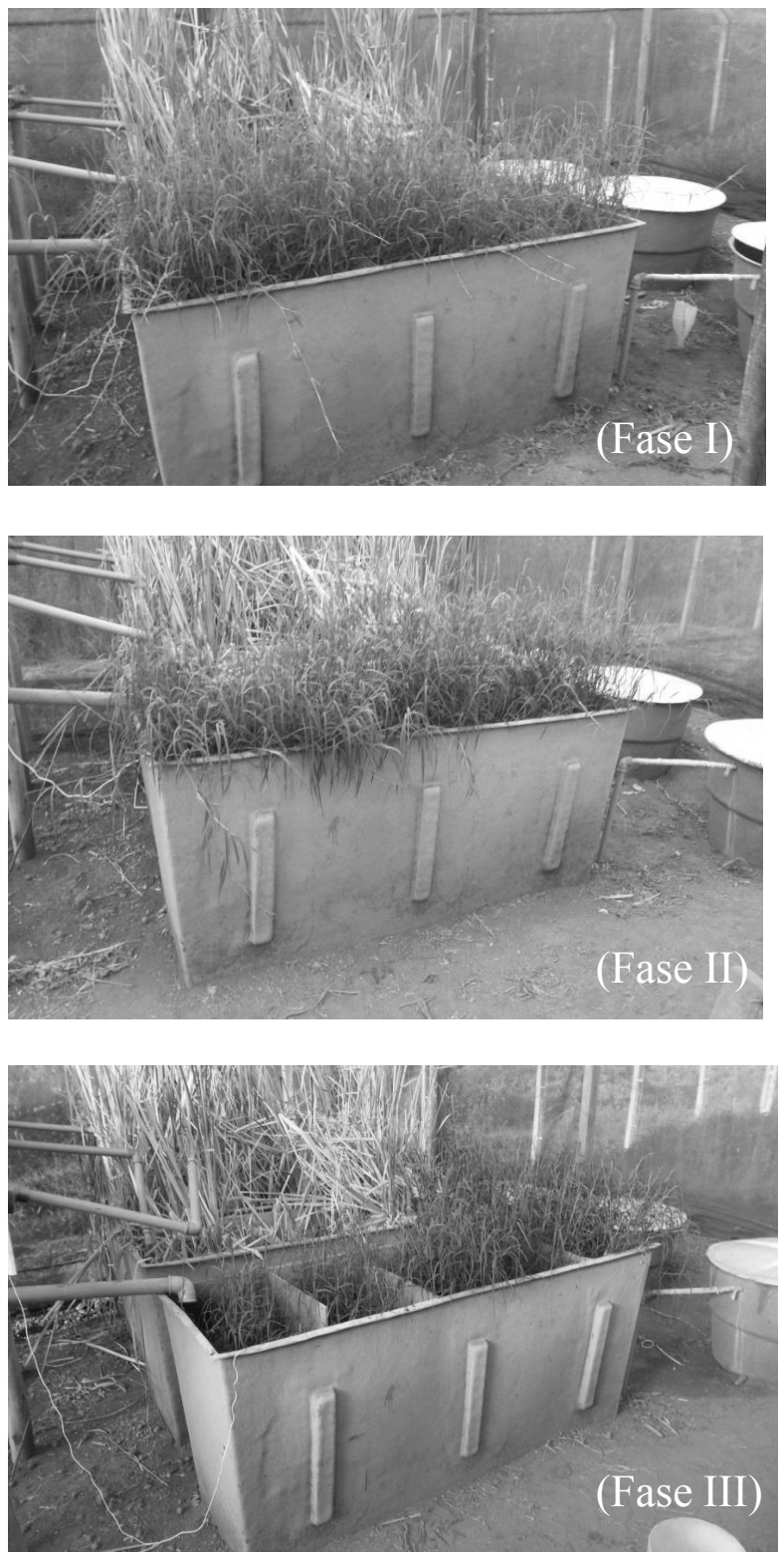

Figura 4. Crescimento do capim-tifton 85 ao longo do SAC em cada fase.

$\mathrm{O}$ outro fator que pode ter contribuído para a redução na produtividade na Fase III refere-se à temperatura inferior à observada nas outras fases. As gramíneas em geral são diretamente afetadas 
pela temperatura, reduzindo seu crescimento. Durante o inverno as forrageiras de verão, como o capim-tifton 85 , têm sua produtividade reduzida pela temperatura (FONTANELI; FONTANELI, 2012).

A produção média de matéria seca nas três fases foi inferior à apresentada na literatura. Fontaneli et al. (2012) relatam que o tifton 85 cultivado em solo, ao receber acima de $550 \mathrm{~kg} \mathrm{ha}^{-1} \mathrm{ano}^{-1}$ de N, apresentam uma produção estimada de $5,7 \mathrm{t} \mathrm{ha}^{-1}$ de matéria seca, por corte.

Em SACs de escoamento vertical, instalados em casa de vegetação, Fia et al. (2014) verificaram a produção acumulada de tifton 85 entre 6,8 e 42,9 t ha ${ }^{-1}$ de matéria seca, quando fertirrigado com efluentes da suinocultura, aplicando taxas de 793 $\mathrm{kg} \mathrm{ha}^{-1} \mathrm{~d}^{-1}$ de DQO. Essa maior produtividade pode estar relacionada ao tipo de escoamento vertical, cujo ambiente não permanece constantemente alagado como naqueles de escoamento horizontal.

Também foi monitorada a condutividade elétrica do líquido em tratamento no SAC, que parece não ter influenciado no desenvolvimento das plantas entre as fases, tendo em vista que os valores afluentes ao SAC foram iguais para as três fases $(p>0,05)$ (Quadro 2). Entretanto, a literatura indica, para utilização na irrigação, que os valores de $\mathrm{CE}$ verificados neste trabalho estão entre os graus de restrição de moderada a severa para a maioria das culturas (AYERS; WESTCOT, 1991). Os valores de CE têm relação direta com os sólidos presentes nos efluentes da suinocultura (SURESH; CHOI, 2011). Diferentemente do observado, em condições brasileiras, Johns et al. (2014) verificaram que mesmo em baixa concentração salina $\left(200 \mathrm{mg} \mathrm{L}^{-1}\right)$, o Cynodon dactylon apresentou sinais de estresse ao alagamento, incluindo o reduzido crescimento, clorose e senescência de tecido foliar.
O aumento das taxas de aplicação de nitrogênio e fósforo no SAC da Fase I para a Fase III (Quadro 1) pode ter proporcionado maior absorção dos nutrientes e consequentes acúmulos no tecido vegetal, como pode ser observado na Figura 3.

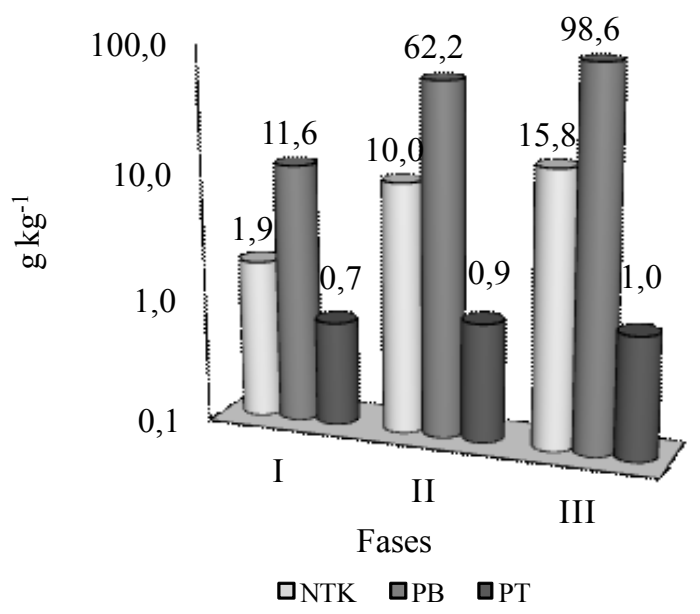

Figura 5. Concentração de nitrogênio total Kjeldahl (NTK), proteína bruta (PB) e fósforo total (PT) na matéria seca (B) do capim-tifton 85 cultivado no SAC.

O conteúdo específico de um determinado elemento no tecido foliar não, necessariamente, reflete a necessidade da planta nestas quantias, pois pode ocorrer a absorção mineral em excesso, dentro de requerimentos nutricionais determinados e específicos, o que é conhecido como o fenômeno do consumo de luxo (ARGENTA et al., 2002; PRIMAVESI et al., 2004). Tal fenômeno é mais evidente quando há disponibilidade de nutrientes, mas outros fatores como salinidade, toxidade por excesso de elementos, ou, ainda, algum elemento limitante, luminosidade, temperatura, entre outros,

Quadro 2. Valores de condutividade elétrica (CE) afluente e efluente do sistema alagado construído (SAC), nas diferentes Fases de condução da unidade de tratamento.

\begin{tabular}{|c|c|c|c|}
\hline & Fases & Afluente do SAC & Efluente do SAC \\
\hline \multirow{3}{*}{$\mathrm{CE}\left(\mathrm{dS} \mathrm{m}^{-1}\right)$} & I & $3,2 \mathrm{a}$ & $3,1 \mathrm{a}$ \\
\cline { 2 - 4 } & II & $2,1 \mathrm{a}$ & $1,9 \mathrm{~b}$ \\
\cline { 2 - 4 } & III & $2,7 \mathrm{a}$ & $2,9 \mathrm{a}$ \\
\hline
\end{tabular}

Médias seguidas de mesma letra na coluna não diferiram entre si pelo Teste de Scott-Knott a 5\% de significância. 
interferem na produção da biomassa reduzindo-a, o que pode ter ocorrido na Fase III comparada à Fase II.

Em sistemas de pastejo, Balsalobre et al. (2003) e Soares et al. (2009) verificaram que diferentes gramíneas, incluindo o capim-tifton 85 , apresentaram "consumo de luxo" de nitrogênio.

Após a aplicação de diferentes doses de nitrogênio e lâminas de irrigação, Rodrigues et al. (2005) obtiveram entre 11 e $15 \%$ de proteína bruta (PB) no tifton 85, enquanto Soares Filho et al. (2002) verificaram $12,5 \%$, valor acima do observado neste trabalho (1,16\% e 9,86\%) (Figura 3). Nesses dois trabalhos cultivou-se o tifton 85 em sistema de pastejo e, muito embora os percentuais sejam mais elevados que no presente artigo, vale ressaltar que o insumo utilizado provém de um passivo ambiental, o qual vem sendo estudado para minimizar os riscos ao ambiente e reutilização, trazendo economia na produção de forragem, além do maior valor de PB na Fase III estar, relativamente, próximo aos encontrados nos trabalhos citados. Em SACs utilizados no tratamento de efluentes da suinocultura, foram verificados valores de PB na parte aérea do capim-tifton 85 entre $12 \%$ e $29 \%$ (MATOS et al., 2010; FIA et al., 2011; FIA et al., 2014).

A quantificação dos teores de PB é importante quando se avalia a possibilidade da utilização do capim-tifton 85 na alimentação animal, pois o desempenho animal responde linearmente à quantidade de proteína na dieta. Os teores de PB diminuem com o avanço da idade da gramínea. Em média, aos 28 dias de cultivo, são alcançados os valores máximos, que se apresentam em média em torno de 15\% (SÁ et al., 2010). Neste trabalho, a ceifa ocorreu aos 47, 32 e 52 dias, respectivamente nas fases monitoradas, assim maiores percentuais de PB poderiam ser obtidos com cortes em menos dias de cultivo.

Fia et al. (2011) e Fia et al. (2014) obtiveram na matéria seca do capim-tifton 85 cultivado em SACs, de escoamento horizontal e vertical, instalados em casa de vegetação, concentrações entre 46 e $27 \mathrm{~g} \mathrm{~kg}^{-1}$ de nitrogênio e 1,7 e 9,7 $\mathrm{g} \mathrm{kg}^{-1}$ de fósforo, respectivamente. Valores esses, superiores aos observados neste trabalho. Provavelmente pelas maiores concentrações destes nutrientes na água residuária utilizada por aqueles autores. O percentual de nutrientes no tecido vegetal depende da disponibilidade de nutrientes, das condições ambientais que podem favorecer a evapotranspiração da planta e o consequente aumento da absorção de nutrientes, intervalo entre os cortes da planta e a biomassa produzida pela planta, que também depende de fatores ambientais.

Com base na produtividade e concentração dos nutrientes determinados na matéria seca, calculou-se a contribuição direta do capim tifton 85 na depuração da ARS. As quantidades extraídas são apresentadas na Figura 4.

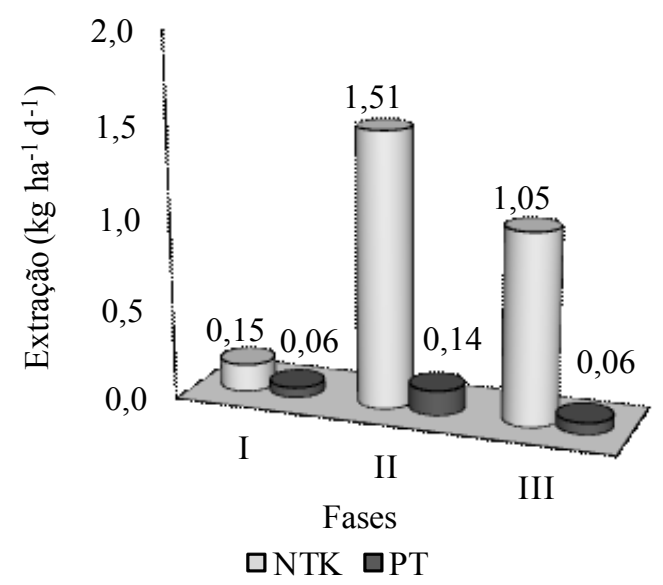

Figura 6. Extração de nitrogênio total Kjeldahl (NTK) e fósforo total (PT) nas três fases do monitoramento.

Em função das altas cargas aplicadas ao sistema, a remoção direta pelas plantas foi considera pequena. Em termos percentuais, o melhor desempenho ocorreu na Fase II, cuja remoção foi de $1,16 \%$ de NTK e $0,27 \%$ PT. Embora a ceifa das plantas em SAC seja importante, a contribuição direta da planta na remoção é baixa em sistemas de escoamento subsuperficial (VYMAZAL, 2007), como o avaliado neste trabalho.

Vymazal (2007) relata que a taxa de remoção pelas plantas varia de 100 a $200 \mathrm{~g} \mathrm{~m}^{-2}$ ano $^{-1}$ de NTK e de 10 a $20 \mathrm{~g} \mathrm{~m}^{-2}$ ano $^{-1}$ de PT, o que em sistemas dimensionados com baixas taxas de aplicação pode ser significativo. Em revisão sobre o tema, Brisson e Chazarenc (2009), Vymazal (2011) e Shelef et al. (2013) verificaram na literatura diferentes efeitos das plantas sobre a remoção de nutrientes, ora positivos, ora sem influência, e até mesmo efeitos negativos. 


\section{CONCLUSÕES}

- Conclui-se que houve aumento nas concentrações de proteína bruta, NTK e PT no tecido do capim-tifton 85 com o aumento da taxa de aplicação superficial de nutrientes, mas a produtividade de matéria seca reduziu na terceira fase, provavelmente, por fatores como diminuição da temperatura e excesso de sólidos retidos na primeira chicana do SAC;

- A taxa de $6.335 \mathrm{~kg} \mathrm{ha}^{-1} \mathrm{~d}^{-1}$ em termos de DQO aplicada na superfície promoveu aparente selamento dos poros no meio suporte, que limitaram o desenvolvimento do capim tifton 85 em termos de matéria seca.

\section{AGRADECIMENTOS}

Os autores agradecem a FAPEMIG pelo financiamento do projeto.

\section{REFERÊNCIAS BIBLIOGRÁFICAS}

ARGENTA, G.; SILVA, P.R.F.; MIELNICZUK, J.; BORTOLINI, C.G. Parâmetros de planta como indicadores do nível de nitrogênio na cultura do milho. Pesquisa Agropecuária Brasileira, Brasília, v.37, n.4, p.519-527, 2002.

AYERS, R.S.; WESTCOT, D.W. A qualidade da água na agricultura. Campina Grande: Editora da UFPB, 1991.

BALSALOBRE, M.A.A.; CORSI, M.; SANTOS,P.M.; VIEIRA, I. ; CÁRDENAS, R.R. Composição química e fracionamento do nitrogênio e dos carboidratos do capim- Tanzânia irrigado sob três níveis de resíduo pós-pastejo. Revista Brasileira Zootecnia, Viçosa, v.32, n.3, p.519-528, maio/jun. 2003.

BRISSON, J.E.; CHAZARENC, F. Maximizing pollutant removal in constructed wetlands: Should we pay more attention to macrophyte species selection? Science of the Total Environment, Amsterdam, v.407, n.13, p.3923-3930, June 2009.
DALMAGO, G.A.; HELDWEIN, A.B.; NIED, A.H.; GRIMM, E.L.; PIVETTA, C.R. Evapotranspiração máxima da cultura de pimentão em estufa plástica em função da radiação solar, da temperatura, da umidade relativa e do déficit de saturação do ar. Ciência Rural, Santa Maria, v.36, n.3, p.785-792, jun. 2006.

FIA, F.R.L.; MATOS, A.T.; FIA, R.; LAMBERT, T.F.; MATOS, M.P. Remoção de nutrientes por Typha latifolia e Cynodon spp. cultivadas em sistemas alagados construídos. Revista Ambiente \& Água, Taubaté, v.6, n.1, p.77-89, abr. 2011a.

FIA, R.; MATOS, A.T.; SCHUERY, F.C.; TEODORO, P.E.P.; LUIZ, F.A.R. Desempenho de filtros anaeróbios no tratamento de águas residuárias da lavagem e descascamento dos frutos do cafeeiro. Revista Engenharia na Agricultura, Viçosa, v.19, n.1, p.62-71, jan./fev. 2011.

FIA, R.; BOAS, R.B.V.; CAMPOS, A.T.; FIA, F.R.L.; SOUZA, E.G. Removal of nitrogen, phosphorus, copper and zinc from swine breeding waste water by bermudagrass and cattail in constructed wetland systems. Revista Engenharia Agrícola, Jaboticabal, v.34, n.1, p.112-113, jan./fev. 2014.

FONTANELI, R.S. FONTANELI, R.S.; SANTOS, H.P.; MARIANI, F.; PIVOTTO, A.C.; SIGNOR, L.R.;ZANELLA, D. Gramíneas forrageiras perenes de verão. In: FONTANELI, R.S.; SANTOS, H.P.; FONTANELI, R.S. (Ed.). Forrageiras para integração lavoura-pecuária-floresta na região sul-brasileira. 2.ed. Brasília: Embrapa, 2012. Cap.8, p.247-295.

FONTANELI, R.S.; FONTANELI, R.S. Qualidade e valor nutritivo de forragem. In: FONTANELI, R.S.; SANTOS, H.P.; FONTANELI, R.S. Forrageiras para integração lavoura-pecuáriafloresta na região sul-brasileira. 2.ed. Brasília: Embrapa, 2012. Cap.1, p.27-49.

JOHNS, C.; RAMSEY, M.; BELL, D.; VAUGHTON, G. Does increased salinity reduce functional depth tolerance of fournon-halophytic wetland macrophyte species? Aquatic Botany, As, v.116, n.1, p.13-18, Maio, 2014. 
KADLEC, R.H.; WALLACE, S.D. Treatment wetlands. Boca Raton: CRC Press, 2008.

MATOS, A.T.; SILVA, D.F.; LO MONACO, P.A.V.; PEREIRA, O. G.Produtividade e composição química do Capim-Tifton 85 submetido a diferentes taxas de aplicação do percolado de resíduo sólido urbano. Engenharia Agrícola, Jaboticabal, v.33, n.1, p.188-200, jan./fev. 2013.

MATOS, A.T.; FREITAS, W.S.; BORGES, A.L.C. Estudo cinético da remoção de matéria orgânica de águas residuárias da suinocultura em sistemas alagados construídos cultivados com diferentes espécies de vegetais. Engenharia Agrícola, Jaboticabal, v.31, n.6, p.1179-1188, nov./dez. 2011.

MATOS, A.T.; FREITAS, W.S.; LO MONACO, P.A.V. Capacidade extratora de diferentes espécies vegetais cultivadas em sistemas alagados utilizados no tratamento de águas residuárias da suinocultura. Revista Ambiente \& Água, Taubaté, v.4, n.2, p.31-45, fev. 2009.

MATOS, A.T.; FREITAS, W.S.; LO MONACO, P.A.V. Eficiência de sistemas alagados construídos na remoção de poluentes de águas residuárias da suinocultura. Ambiente \& Água, Taubaté, v.5, n.2, p.119-132, dez. 2010.

OLIVEIRA, A.P.P. ROSSIELLO, R.O.P.; GALZERANO, L.; COSTA JÚNIOR, J.B.G.; SILVA, R.P.; MORENZ, M.J.F. Respostas do capim-Tifton 85 à aplicação de nitrogênio: cobertura do solo, índice de área foliar e interceptação da radiação solar. Arquivo Brasileiro de Medicina Veterinária e Zootecnia, Belo Horizonte, v.62, n.2, p.429-438, abr. 2010.

OSALIYA, R.; KANSIIME, F.; ORYEM-ORIGA, H.; KATEYO, E. The potential use of storm water and effluent from a constructed wetland for re-vegetating a degraded pyrite trail in Queen Elizabeth National Park, Uganda. Physics and Chemistry of the Earth, Bristol, v.36, n.1-4, p.842-852, 2011.

PEREIRA, O.G. ROVETTA, R.; RIBEIRO, K.G.; SANTOS, M.E.R.; FONSECA, D.M.; CECON,
P.C. Crescimento do capim-tifton 85 sob doses de nitrogênio e alturas de corte. Revista Brasileira de Zootecnia, Viçosa, v.41, n.1, p.30-35, jan. 2012.

PRIMAVESI, A.C. PRIMAVESI, O; CORRÊA, L.A.; CANTARELLA, H.; SILVA, A.G.; FREITAS, A.R.; VIVALDI, L.J. Adubação nitrogenada em capim-coastcross: efeitos na extração de nutrientes e recuperação aparente do nitrogênio. Revista Brasileira de Zootecnia, Viçosa, v.33, n.1, p.6878, jan./fev. 2004.

RODRIGUES, B.H.N.; LOPES, E.A.; MAGALHÃES, J.A. Teor de proteína bruta do Cynodon spp. cv. Tifton 85 sob irrigação e adubação nitrogenada, em Parnaíba, Piauí. Teresina: Embrapa Meio-Norte, 2005.

SÁ, J.F.; PEDREIRA, M.S.; SILVA, F.F.; BONOMO, P. ; FIGUEIREDO, M.P.; MENEZES, D.R.; ALMEIDA, T.B. Fracionamento de carboidratos e proteínas de gramíneas tropicais cortadas em três idades. Arquivo Brasileiro de Medicina Veterinária e Zootecnia, Belo Horizonte, v.62, n.3, p.667-676, jun. 2010.

SHELEF, O.; GROSS, A.; RACHMILEVITCH, $\mathrm{S}$. Role of plants in a constructed wetland: current and new perspectives. Water, Washington, v.5, n.2, p.405-419, 2013.

SILVA, F.C. da. Manual de análises químicas de solos, plantas e fertilizantes. 2.ed. rev. e ampl. Brasília: Embrapa, 2009.

SOARES, A.B. Sartor, L.R.; ADAMI, P.F.; VARELLA, A.C.; FONSECA, L.; MEZZALIRA, J.C. Influência da luminosidade no comportamento de onze espécies forrageiras perenes de verão. Revista Brasileira de Zootecnia, Viçosa, v.38, n.3, p.443-451, mar. 2009.

SOARES FILHO, C.V., RODRIGUES, L.R.A., PERRI, S.H.V. Produção e valor nutritivo de dez gramíneas forrageiras na região Noroeste do Estado de São Paulo. Acta Scientiarum, Maringá, v.24, n.5, p. 1377-1384, 2002. 
SURESH, A, CHOI, H.L. Estimation of nutrients and organic matter in Korean swine slurry using multiple regression analysis of physical and chemical properties. Bioresource Technology, Essex, v.102, n.19, p.8848-8859, Oct. 2011.

VYMAZAL, J. Removal of nutrients in various types of constructed wetlands. Science of the Total Environment, Amsterdam, v.380, n.1-3, p.48-65, July 2007

VYMAZAL, J. Emergent plants used in free water surface constructed wetlands: a review. Ecological Engineering, Oxford, v.61, p.582-592, Dec. 2013.

VYMAZAL, J. Constructed wetlands for wastewater treatment: five decades of experience. Environmental Science \& Technology, Easton, v.45, n.1, p.61-69, Aug. 2010.

VYMAZAL, J. Constructed wetlands for wastewater treatment: five decades of experience. Environmental Science \& Technology, Easton, v.45, n.1, p.61- 69, 2011. 